\title{
The Directions of Productivity Improvement of Fiscal Policy under Present-day Conditions
}

\author{
Seymur Orujov \\ Department of Finance, Azerbaijan State Economic University \\ Istiglaliyyet Street 6, Baku, AZ1001, The Republic of Azerbaijan \\ Tel: 994-50-250-4641_E-mail: sorujov@box.az
}

Received: April 29, 2011

Accepted: June 30, 2011 Published: December 1, 2011

doi:10.5539/ijbm.v6n12p293

URL: http://dx.doi.org/10.5539/ijbm.v6n12p293

\begin{abstract}
The paper is devoted to the investigation of the questions connected with the directions of productivity improvement of fiscal policy under present-day conditions. It is shown that for the correct and timely solution of the problems standing before the policy of the budget expenses, it is required an exact and deep approach to the essence, purpose and implementation method of the financial policy and its consisting elements. It is obviously that study of practices of the other foreign countries which has the budget institutions that carries out a successful activity can provide many advantages for the developing of more productive and transparent budget system of the Republic of Azerbaijan. The practice shows that the separation of the financial policy from economy results in serious economic difficulties and it restrains the realization of existent possibilities. The scientific approach to the development of the financial policy is the main subject for its compliance with social development regularity. Violation of this important demand may result in great loss in the national economy.
\end{abstract}

Keywords: Fiscal policy, Finance, Budget

\section{Introduction}

Under the present market relations the implementation of financial policy and general development direction of a country depends on the formation and organization of the fiscal management as well as fiscal policy. This factor is of a great importance on the global financial crisis terms occurred all over the world. Because the market economy is generated first of all on the basis of the financial credit procedure. The influence on economical processes by a government mainly is implemented by means of fiscal policy. Just from this point of view the formation of the budget relations is of a great importance.

The budget relations have an objective aspect. It is connected with that each year the government must concentrate a certain part of the national income, and allocate it again for extension of overproduction, provision of the social-cultural requirements of citizens, solution of the defense issues, covering of the general expenses of the state administration structure.

One of the important aspects of the fiscal management is a comprehensive approach to the procedures applied for all financial cycles, as well as other part of the economic policy as money-credit, pricing relations occurred during development of a fiscal policy. By means of the fiscal policy the financial resources which are necessary for fulfillment of requirements of a society for its development are fully mobilized. From this point of view the fiscal policy is directed to the implementation of a reasonable condition for the activation of the business activity. Traditionally a scientific foundation and successful implementation of the fiscal management makes good results. It results in the improvement of living standards of the population (Hasanli, 2009). In the process of the preparation and realization of the fiscal policy thee main attention is paid to the improvement of the material and moral living standards of the population, expansion of the social service, control on the financial resources generated by the taxes paid by the population.

\section{The Directions of Productivity Improvement of Fiscal Policy under the Present-Day Conditions}

As is generally known profitability indicator of the application of the fiscal policy is the state budget. There is a direct connection between the state budget and gross domestic product. Let us imagine that the state purchase permanently increases when the amount of the budget income is permanent. In such a case a budget default will occur. Inversely, if the income exceeds the budget expenses, there will appear a positive balance of the budget. Moreover the amount of the national production influences to the amount of the budget default. During decline 
period, $i$. e. when a new gross domestic product (GDP) comes down, it appears a budget default as a rule. Inversely, when GDP increases, there will appear a positive balance of the budget. But not always the increase of GDP results in increase of budget incomes (Safarov, 2000).

If there is a surplus in the state budget and if the government collects more taxes in comparison with its expenses, it means that the state gets more income in comparison with the macroeconomic turnover. Consequently the amount of GDP is restrained. Inversely, if there is a budget default that is the expenses exceeds the income, the state spends more in comparison with its collected financial means and it means that the consuming capacity is increased and the amount of the GDP increases.

As a result it is obviously that we can not consider the budget default as the indicator of the unreasonable fiscal policy. In such a case it is important to abandon the tradition of keeping balance. It is important for reason that the surplus case of expenses in comparison with the income to stimulate the economy. The practice shows that a government intentionally makes a condition the budget default to be great in order to find a way out from the economic crisis. The dynamics of the budget default (surplus) and share of the budget default in GDP (in Million Azerbaijan Manats) are shown in Table. According to the information showed the highest level of the budget default is observed in the forecast indicator for 2010.

Actually if the state expends more than it collects, then the consuming capacity is increased in the society. In other words the population consumes more, the enterprises sell more products (work or services) and the main aspect is that the movement of the resources is accelerated and as a result the employment is increased.

Therefore the budget default is useful during unemployment period, but it is some dangerous during development. So as the demand exceeds the supply because of resource lack, the budget default brings to inflation (Bolshakov, 1994). In order to control the inflation first of all it is important to create a reasonable budget surplus. For this purpose it is important to decrease the management expenses as far as possible and to keep stability of the tax rate in the condition of a strong inflation pressure. It is also important to restrain the consumer credits, accelerate the selling measures of the deposit borrowings, restrictedly use of price control and rationalization in the different spheres of the economy.

The crisis situation of economy can only be avoided by increasing of the business activity and investigation demands. But in its turn it requires increase of the state expenses and decrease of income. Increasing of the state expenses and decreasing of income serves for the realization of stimulating purpose of the economic activity which is in the decline condition. More years ago J. M. Keynz stated that in the cyclic decline period of the economy and in the condition of deficit budget the financing has a crucial and important role in exhilaration of a business activity, stimulation of investing requirements (Goreglyad, 2002). So such stimulating economic policy requires necessity of appearance of the budget default. Appeared budget default should be terminated by certain means. In such a case it is important to select methods which will not balance the stimulating effects of the economic policy.

In the condition of an economic crisis it has also an invisible default based on the illegal fiscal activity (invalid budget) of the Central Bank, state institutions and commercial banks as well besides of definition of the budget default. The invisible budget default decreases the amount of the actual budget default and the governmental debts. This is traditionally carried out purposefully in a pre-election period in some countries.

We think that the absolute measures of the budget default can not act as a reasonable macroeconomic indicator. Borrowing of debts traditionally increases by increasing of GDP. As the budget default is equal to the financing, it can be determined as a difference between them after addition of the remainder of the liquid financial means to the covering of the general debts.

The budget default is connected with a number of macroeconomic measures. So, the reproductive rate of these economic indicators has an effective influence to the budget default. The existence of the initial budget default is considered to be the main aspect for the increasing of the "debt severity". There are two main reasons for being of the governmental debts as a great problem. First of all increasing of the governmental debts may decrease the capital investment in the economy. The other reason is the following. Paying of percentage may gradually increase in connection with the existence of governmental debts in the economy. The government should permanently pay the interests on debts (Guliyev, 1999). One of the ways out of it is increasing of taxes. As a result also this step can negatively influence to the economy. During the government covers its debts gets its debt obligations again by submitting of its income to the money market. Money supply increases and interest rate decreases and as a result it just stimulates the investigation and consumption.

The negative influence of the lower level of forecast in comparison with the actual default on the monetary sector is also explained with that it keeps off development of the short-term state equity market. As the framework of this market is little it restricts the monetary regulating possibility of the Central Bank. The experts 
of the International Currency Foundation confirm, too that the state bonds should be emitted not only for the fiscal but also for the monetary purposes (Surkov \& Yaremchuk, 2004).

As the actual state budget default is less than forecast default it is impossible to increase the emission of the state short-term obligations as a source of its covering.

Another covering method of the budget default is increasing of tax incomes to the state budget. The problem of increasing of tax incomes to the state budget exceeds the limits of financing of the budget default. So, in the long-term perspective it is permitted enlarging of the base of involving in the tax and decreasing of the tax rates. In the short-term condition the decreasing of the tax rates accompanies the followings:

- Decreasing of the reconstruction and stability level;

- Increasing of "drive out effect" in the non-governmental sector against the background of increase of the interest rate was resulted in a reaction in the monetary market; this process is accompanied by an economical activity, demand and supply for money permanently increases.

- Increase of the budget default is connected with the decline of tax and tax rates including to the budget.

Optimal generation of the budget in the period of market economy, decreasing of its default and weakening of its dependence of the foreign financial organization are the important issue before the governments as a significant economic problem.

Taking into consideration that the budget is a diversified parameter, it would not be right to consider it only as an economic instrument. Just for this reason the budget process have to be observed not from only one point of view. Traditionally if the country with a strong economy undertakes to solve the majority of public problems it should possess a larger budget in comparison with GDP. For this purpose it is reasonable to take the following measures in the future:

- the balance appeared between the budget and macro-economy should be improved. In a normal case a budget is generated thanks to the activity of the economy. Meanwhile the budget actively influences on economy and the economic model of a country is created depending on this influence. In such a case it is difficult to understand whether budget or the general economy is of importance;

- the problem of poverty should be solve by means of the budget. Certainly growth of many new places of employment is a positive case. The problem of poverty can be absolutely solved only by this way. The budget should not undertake the load which is not inherent in it. The economy should solve the problem of poverty and the budget should relatively alleviate this problem;

- the growth of the budget income should either be generated by the taxes collected from the industrial spheres or by the income tax collected in the result of application of the necessary general income declaration. When there are great conditions in the sphere of consumer it is not reasonable to collect taxes from a new manufacturer who had just taken his place in the sphere of production.

Economical and advantageous allocation of the budget expenses is one of the main missions. On terms of global financial crisis occurred all over the world the government was able to overcome the most important 3 problems: the national currency of Azerbaijan could save its value and it was prevented from devaluation of manat; Although the oil income was decreased in comparison with the previous years, the budget expenses were saved and prevented from exceeding of predicted limits and in spite of closing of the foreign finance resources the banks of the country was able to save its existence and even one bank had not become bankrupt.

It is worth to say that in the last years the government is going rapidly to increase the expenses of investment type at the same time with the expenses of social type in our country. Increasing of the investment expenses which are the classical means of economic regulation has created a favorable opportunity for the long-term expansion of whole requirement which stimulates the increase factor in the economy. Meanwhile it is important to say that the total amount of social type expenses exceeds for $40 \%$ than the budget expenses. This creates a condition for the maximum social defense of the social stratum of population.

In the last years the budget expenses of the Republic of Azerbaijan is developing with a growing speed. For improvement of the management of the budget expenses of the state it is important to continue activity on the following direction:

- On the direction of the developing of legislation base providing productively to use the state expenses, to improve the structure of the budget expenses and to increase the transparency of expenses;

- Providing of the investment and social orientation of the expenses;

- By means of effective use of the budget resources to develop the spheres which are significant for the economic regions, to increase activities of the production enterprises, to stimulate the production of 
export type goods, to increase the employment level of the population by means of development of the local ownership, to improve the vital activity and to provide the dynamic development of the state economy;

- In order to reliably and productively use the budget expenses to accelerate the control on the stock house, to provide flexibly management of indebtedness at the budget organizations;

\section{Conclusion}

According to the aforesaid we come to the conclusion that for the correct and timely solution of the problems standing before the policy of the budget expenses, it is required an exact and deep approach to the essence, purpose and implementation method of the financial policy and its consisting elements. From this point of view the practice of implementation of the financial activities in foreign countries is of a great interest. It is obviously that study of practices of the other foreign countries which has the budget institutions that carries out a successful activity can provide many advantages for the developing of more productive and transparent budget system of the Republic of Azerbaijan.

Certainly only such a scientific approach, learning of all factors which determine the budget policy, can ensure uninterrupted relation with the objective economic terms thanks to the relative independence of this policy. The practice shows that the separation of the financial policy from economy results in serious economic difficulties and it restrains the realization of existent possibilities. The scientific approach to the development of the financial policy is the main subject for its compliance with social development regularity. Violation of this important demand may result in great loss in the national economy.

\section{References}

Bolshakov, S.V. (1994). Financial policy and financial regulation of the economy of the transition period. Summary of the dissertation for the academic degree of doctor of economic sciences. Moscow.

Goreglyad, V.P. (2002). Budget as a financial regulator of the economic development. Moscow.

Guliyev, T. A. (1999). Regulated market economy. Baku.

Hasanli, M. Kh. (2009). Theoretical aspects of influence of the government in the economical development by means of taxes. Economic sciences: theory and practice (Azerbaijan State Economic University), 3-4,129-134.

Safarov, S. (2000). Strategy of the economic policy. The conceptual bases. Baku: Azerneshr.

Surkov, M. S., \& Yaremchuk, N. V. (2004). The institutions and instruments of the budget-tax and money-credit economic regulation. A teaching aid. Moscow: Publishing house "Gorodech".

Table 1. Dynamics of Budget Default (surplus) and Share of Budget Default in GDP

In million Azerbaijan Manats

\begin{tabular}{|l|c|c|}
\hline \multicolumn{1}{|c|}{ Years } & $\begin{array}{c}\text { Budget default(-), } \\
\text { surplus (+) }\end{array}$ & $\begin{array}{c}\text { Share of budget default } \\
\text { in GDP }\end{array}$ \\
\hline 2003 & -8.5 & 0.2 \\
\hline 2004 & -19.8 & 0.2 \\
\hline 2005 & -85.5 & 0.7 \\
\hline 2006 & 91.5 & 0.5 \\
\hline 2007 & -52.9 & 0.2 \\
\hline 2008 & 82.0 & 0.2 \\
\hline 2009 & -242 & 0.7 \\
\hline 2010 (forecast) & -770.3 & 2.0 \\
\hline 2011 (forecast) & -687 & 1.7 \\
\hline
\end{tabular}

